\title{
EDITORIAL
}

\section{Cerebral oximetry in cardiac arrest: a potential role but with limitations}

\author{
Claudio Sandroni ${ }^{1}$, Sam Parnia ${ }^{2}$ and Jerry P. Nolan ${ }^{3,4^{*}}$ (i)
}

(0) 2019 Springer-Verlag GmbH Germany, part of Springer Nature

In patients with cardiac arrest (CA) cerebral oximetry has emerged as a real-time indicator of oxygen delivery to the brain which could be used to optimise cerebral oxygenation during and after cardiopulmonary resuscitation (CPR) (Table 1). Near-infrared spectroscopy (NIRS) emits infrared light (700-950 nm wavelength), which is not absorbed significantly by melanin in the skin and enables non-invasive monitoring of the regional haemoglobin oxygen saturation in the brain $\left(\mathrm{rSO}_{2}\right)$. NIRS electrodes are placed on the scalp above the frontal cortex and the sampling volume is located about $2 \mathrm{~cm}$ underneath the skull [1]. Since about $70 \%$ of the sampled blood is venous, normal $\mathrm{rSO}_{2}$ is approximately $60-80 \%$. Unlike arterial pulse oximetry, $\mathrm{rSO}_{2}$ can still be measured when blood flow is nonpulsatile or even absent, enabling NIRS to be used during CA. Unlike the electroencephalogram, NIRS is not susceptible to motion artefact generated by CPR.

\section{Use of cerebral oximetry during cardiac arrest}

Higher $\mathrm{rSO}_{2}$ values during CPR are associated with significantly higher rates of return of spontaneous circulation (ROSC). In a review of 26 observational studies (1995-2016), the averaged mean $\mathrm{rSO}_{2}$ in patients achieving ROSC was $41 \pm 12 \%$ vs. $30 \pm 12 \%$ for those without ROSC ( $p=0.009$ ) [2]. However, there was wide overlap of $\mathrm{rSO}_{2}$ values between the two groups. Among 183 in-hospital CA (IHCA) patients [3], a $25 \% \mathrm{rSO}_{2}$ cutoff predicted no ROSC with 100 [94-100]\% specificity, while a $65 \% \mathrm{rSO}_{2}$ cut-off predicted ROSC with 99 [95$100] \%$ specificity. However, these values corresponded to the extremes of the distribution, so that the relevant

\footnotetext{
*Correspondence: jerry.nolan@nhs.net

${ }^{3}$ Department of Anaesthesia, Royal United Hospital, Bath, UK

Full author information is available at the end of the article
}

sensitivities were low $(13[8-21] \%$ and $21[12-33] \%$, respectively).

During CPR, $\mathrm{rSO}_{2}$ trends appear to be better predictors of ROSC than mean values or values recorded at single time points. In a study on 329 out-of-hospital CA (OHCA) [4] $\mathrm{rSO}_{2}$ increased steadily during resuscitation in both ROSC and non-ROSC patients, but the increase was twice as high in the ROSC group [median 17\% (IQR $6-29$ ) vs. 8\% (IQR 2-13); $p<0.001$ ]. After adjustment for major confounders, a greater than $15 \%$ increase in $\mathrm{rSO}_{2}$ during CPR was the best predictor of ROSC (odds ratio [OR] 4.88 [2.79-8.54]).

As has been observed for end-tidal carbon dioxide $\left(\mathrm{ETCO}_{2}\right)$, an abrupt increase in $\mathrm{rSO}_{2}$ values during $\mathrm{CPR}$ indicates that ROSC has occurred [5]. In a study on 53 OHCA patients, 22 (42\%) had ROSC after a mean of 22.5 min of CPR; when ROSC occurred, the median $\mathrm{rSO}_{2}$ increased from $22.5 \%$ [16-35] to $51 \%$ [39-55] in $3 \mathrm{~min}$ [6]. A potential advantage of $\mathrm{rSO}_{2}$ compared with $\mathrm{ETCO}_{2}$ for monitoring during CPR is that detection of the $\mathrm{rSO}_{2}$ signal does not require advanced airway management.

In a study on IHCA [3], time with $\mathrm{rSO}_{2}>50 \%$ during CPR best predicted favourable neurological outcome after resuscitation (cerebral performance category 1-2), suggesting that $\mathrm{rSO}_{2}$ may reflect the quality of cerebral oxygenation and perfusion during CPR. In another study, among 92 OHCA patients who arrived at the emergency department with ongoing CPR, the rate of neurological recovery was $50 \%$ in those with $\mathrm{rSO}_{2}>40 \%, 22 \%$ in those with $\mathrm{rSO}_{2} 26-40 \%$, and $0 \%$ in those with $\mathrm{rSO}_{2} 25 \%$ or less [7].

\section{Cerebral oximetry in post-resuscitation care}

Optimising cerebral oxygenation and perfusion is one of the mainstays of post-resuscitation care. Autoregulation of cerebral blood flow (CBF) is lost in about one third of comatose CA survivors [8], while in others the

\section{6 Springer}


Table 1 Cerebral oximetry $\left(\mathrm{rSO}_{2}\right)$ in cardiac arrest

\begin{tabular}{|c|c|c|}
\hline Potential applications & Results/advantages & Limitations \\
\hline Monitoring brain oxygenation & $\begin{array}{l}\text { NIRS measures the regional oxygen saturation }\left(\mathrm{rSO}_{2}\right) \text { by } \\
\text { analysing the intensity of infrared light backscattered } \\
\text { from tissue located about } 2 \mathrm{~cm} \text { underneath a probe } \\
\text { placed on the frontal scalp } \\
\mathrm{rSO}_{2} \text { can be detected even when flow is nonpulsatile or } \\
\text { absent, as in cardiac arrest }\end{array}$ & $\begin{array}{l}\text { There is a significant risk of contamination of the NIRS } \\
\text { signal by extracerebral sources }[1,13]\end{array}$ \\
\hline Prediction of ROSC during CPR & $\begin{array}{l}\text { In a systematic review of } 26 \text { studies [2], the averaged } \\
\text { mean } \mathrm{rSO}_{2} \text { in patients with ROSC was } 41 \pm 12 \% \text { vs. } \\
30 \pm 12 \% \text { for those without ROSC ( } p=0.009 \text { ) } \\
\text { In a study on } 183 \text { IHCA [3], a } \geq 65 \% \text { rSO }{ }_{2} \text { cut-off had } 99 \\
\text { [95-100]\% specificity for ROSC, while a } \leq 25 \% \text { rSO } \\
\text { cut-off had } 100 \text { [94-100]\% specificity for no ROSC } \\
\text { In a study on } 329 \text { OHCA, a } 15 \% \text { increase of rSO } \text { dur- }_{2} \text { dur- } \\
\text { ing CPR was the best predictor of ROSC (OR } 4.88 \\
\text { [2.79-8.54]) }\end{array}$ & $\begin{array}{l}\text { There was a wide overlap of averaged } \mathrm{rSO}_{2} \text { values } \\
\text { between ROSC and no-ROSC studies } \\
\text { High specificities only at the extremes of the distribution. } \\
\text { The relevant sensitivities were low ( } 21 \text { [12-33]\% and } 13 \\
\text { [8-21]\%, respectively) }\end{array}$ \\
\hline $\begin{array}{l}\text { Targeting MAP to optimise } \\
\text { cerebral perfusion after } \\
\text { resuscitation }\end{array}$ & $\begin{array}{l}\text { Optimal MAP is defined as the one which minimises the } \\
\text { correlation coefficient (COX) between MAP and } \mathrm{rSO}_{2} \\
\text { (optimal autoregulation) } \\
\text { Observational evidence }[8,9,11 \text { ] showed that deviation } \\
\text { from optimal MAP is associated with worse neurologi- } \\
\text { cal outcome or lower survival in both children and } \\
\text { adults }\end{array}$ & $\begin{array}{l}\text { There are no interventional studies showing that targeting } \\
\text { a specific MAP improves neurological outcome after CPR } \\
\text { The relationships between } \mathrm{rSO}_{2} \text {, CBF and neurological } \\
\text { outcome are not fully understood and deserve further } \\
\text { investigation }\end{array}$ \\
\hline
\end{tabular}

CBF cerebral blood flow, CPR cardiopulmonary resuscitation, IHCA in-hospital cardiac arrest, MAP mean arterial pressure, OHCA out-of-hospital cardiac arrest, $R O S C$ return of spontaneous circulation, $\mathrm{rSO}_{2}$ regional oxygen saturation of the brain

zone of autoregulation is narrowed and right-shifted [9] so that CBF is maintained consistent and independent from mean arterial pressure (MAP) only within a narrower and higher MAP range. In clinical studies the optimal MAP has been identified as that where the correlation coefficient between $\mathrm{rSO}_{2}$ and MAP (termed as $\mathrm{COX}$ ) is minimal in the individual patient [9]. In children resuscitated from $\mathrm{CA}$, deviations from optimal MAP have been associated with worse neurological outcome $[8,10]$. In a study on 51 resuscitated comatose adults [9], the time spent below the optimal MAP was associated with a lower likelihood of survival (OR 0.97 [0.96-0.99], $p=0.02$ ).

Cerebrovascular reactivity to $\mathrm{CO}_{2}$ is generally preserved after $\mathrm{CA}$ and manipulating arterial partial pressure of carbon dioxide $\left(\mathrm{PaCO}_{2}\right)$ may be used in order to optimise $\mathrm{CBF}$ and brain oxygenation. In the recent COMACARE randomised pilot trial [11], a high-normal (5.8-6.0 kPa) $\mathrm{PaCO}_{2}$ was associated with higher $\mathrm{rSO}_{2}$ than low-normal $(4.5-4.7 \mathrm{kPa}) \mathrm{PaCO}_{2}$ in comatose resuscitated patients. A larger randomised trial (NCT03114033) comparing mild hypercarbia (6.7$7.3 \mathrm{kPa}$ ) with normocarbia after CA is currently ongoing.

\section{Current limitations and future perspectives}

The association between higher $\mathrm{rSO}_{2}$ values during $\mathrm{CPR}$ and the rates of ROSC or neurological recovery suggests that $\mathrm{rSO}_{2}$ could be used as a physiological target to optimise CPR quality. However, the nature of this association is not completely clear. In fact, since NIRS signals can be contaminated from extracerebral circulation [12], $\mathrm{rSO}_{2}$ values during $\mathrm{CPR}$ may reflect whole-body rather than brain perfusion. In addition, patients who achieve ROSC usually show higher $\mathrm{rSO}_{2}$ values from the beginning of the resuscitation attempt [2], so that it is not clear whether a higher $\mathrm{rSO}_{2}$ in these patients reflects more effective CPR or, instead, other favourable factors, such as witnessed status or a shorter no-flow time.

Although lower nadir $\mathrm{rSO}_{2}$ levels have been associated with worse neurological outcome in resuscitated comatose patients [13], observational studies did not show an association between mean $\mathrm{rSO}_{2}$ in the early post-resuscitation phase and neurological outcome. In the COMACARE trial, changes in mean $\mathrm{rSO}_{2}$ were not associated with differences in the levels of neuron-specific enolase, a marker of neuronal ischaemia. However, $\mathrm{rSO}_{2}$ values were within normal values in all study groups. A limitation of this and other investigational models, such as the ones based on $\mathrm{COX}$, is that the relationship between $\mathrm{rSO}_{2}$ and $\mathrm{CBF}$ is not well known, although a recent study has shown that $\mathrm{rSO}_{2}$ is positively correlated with cerebral perfusion pressure evaluated noninvasively using transcranial Doppler [14]. Further research is required to determine if cerebral oximetry is of real value in resuscitation, but based on current evidence it is not ready for routine clinical use. 


\section{Author details}

${ }^{1}$ Istituto Anestesiologia e Rianimazione, Fondazione Policlinico Universitario "Agostino Gemelli" IRCCS, Università Cattolica del Sacro Cuore, Largo Francesco Vito, 1, 00168 Rome, Italy. ${ }^{2}$ Division of Pulmonary, Critical Care and Sleep Medicine, New York University Langone Medical Center, 462 First Avenue, OBV, 6th Floor, CD621, New York, NY 10016, USA. ${ }^{3}$ Department of Anaesthesia, Royal United Hospital, Bath, UK. ${ }^{4}$ Warwick Medical School, University of Warwick, Coventry CV4 7A, UK

\section{Compliance with ethical standards}

\section{Conflicts of interest}

Sandroni: none to declare. Parnia: none to declare. Nolan: Editor-in-Chief of Resuscitation

\section{Ethical approval}

An approval by an ethics committee was not applicable.

\section{Publisher's Note}

Springer Nature remains neutral with regard to jurisdictional claims in published maps and institutional affiliations.

Received: 24 December 2018 Accepted: 15 February 2019

Published online: 6 March 2019

\section{References}

1. Skhirtladze-Dworschak K, Dworschak M (2013) Cerebral oximetry and cardiac arrest. Semin Cardiothorac Vasc Anesth 17:269-275

2. Schnaubelt S, Sulzgruber P, Menger J, Skhirtladze-Dworschak K, Sterz F, Dworschak M (2018) Regional cerebral oxygen saturation during cardiopulmonary resuscitation as a predictor of return of spontaneous circulation and favourable neurological outcome-a review of the current literature. Resuscitation 125:39-47

3. Parnia S, Yang J, Nguyen R, Ahn A, Zhu J, Inigo-Santiago L, Nasir A, Golder K, Ravishankar S, Bartlett P, Xu J, Pogson D, Cooke S, Walker C, Spearpoint K, Kitson D, Melody T, Chilwan M, Schoenfeld E, Richman P, Mills B, Wichtendahl N, Nolan J, Singer A, Brett S, Perkins GD, Deakin CD (2016) Cerebral oximetry during cardiac arrest: a multicenter study of neurologic outcomes and survival. Crit Care Med 44:1663-1674

4. Genbrugge C, De Deyne C, Eertmans W, Anseeuw K, Voet D, Mertens I, Sabbe M, Stroobants J, Bruckers L, Mesotten D, Jans F, Boer W, Dens J
(2018) Cerebral saturation in cardiac arrest patients measured with nearinfrared technology during pre-hospital advanced life support. Results from Copernicus I cohort study. Resuscitation 129:107-113

5. Sandroni C, De Santis P, D'Arrigo S (2018) Capnography during cardiac arrest. Resuscitation 132:72-77

6. Prosen G, Strnad M, Doniger SJ, Markota A, Stozer A, Borovnik-Lesjak V, Mekis D (2018) Cerebral tissue oximetry levels during prehospital management of cardiac arrest—a prospective observational study. Resuscitation 129:141-145

7. Ito N, Nanto S, Nagao K, Hatanaka T, Nishiyama K, Kai T (2012) Regional cerebral oxygen saturation on hospital arrival is a potential novel predictor of neurological outcomes at hospital discharge in patients with out-of-hospital cardiac arrest. Resuscitation 83:46-50

8. Sekhon MS, Griesdale DE (2017) Individualized perfusion targets in hypoxic ischemic brain injury after cardiac arrest. Crit Care 21:259

9. Ameloot K, Genbrugge C, Meex I, Jans F, Boer W, Vander Laenen M, Ferdinande B, Mullens W, Dupont M, Dens J, DeDeyne C (2015) An observational near-infrared spectroscopy study on cerebral autoregulation in post-cardiac arrest patients: time to drop 'one-size-fits-all' hemodynamic targets? Resuscitation 90:121-126

10. Lee JK, Brady KM, Chung SE, Jennings JM, Whitaker EE, Aganga D, Easley RB, Heitmiller K, Jamrogowicz JL, Larson AC, Lee JH, Jordan LC, Hogue CW, Lehmann CU, Bembea MM, Hunt EA, Koehler RC, Shaffner DH (2014) A pilot study of cerebrovascular reactivity autoregulation after pediatric cardiac arrest. Resuscitation 85:1387-1393

11. Jakkula P, Reinikainen M, Hastbacka J, Loisa P, Tiainen M, Pettila V, Toppila J, Lahde M, Backlund M, Okkonen M, Bendel S, Birkelund T, Pulkkinen A, Heinonen J, Tikka T, Skrifvars MB, COMACARE study group (2018) Targeting two different levels of both arterial carbon dioxide and arterial oxygen after cardiac arrest and resuscitation: a randomised pilot trial. Intensive Care Med 44:2112-2121

12. Caccioppola A, Carbonara M, Macri M, Longhi L, Magnoni S, Ortolano F, Triulzi F, Zanier ER, Zoerle T, Stocchetti N (2018) Ultrasound-tagged nearinfrared spectroscopy does not disclose absent cerebral circulation in brain-dead adults. Br J Anaesth 121:588-594

13. Bougle A, Daviaud F, Bougouin W, Rodrigues A, Geri G, MorichauBeauchant T, Lamhaut L, Dumas F, Cariou A (2016) Determinants and significance of cerebral oximetry after cardiac arrest: a prospective cohort study. Resuscitation 99:1-6

14. Taccone FS, Crippa IA, Creteur J, Rasulo F (2018) Estimated cerebral perfusion pressure among post-cardiac arrest survivors. Intensive Care Med 44:966-967 